\title{
Isolated Pulmonary Metastasis Presenting with an CEA Elevation Five Years After Radical Prostatectomy
}

\author{
Yuksel URUN ${ }^{1}$, Gungor UTKAN ${ }^{1}$, Sibel PERCINEL ${ }^{2}$, Ayten K. CANGIR ${ }^{3}$, Mutlu DOGAN ${ }^{1}$, Fikri ICLI ${ }^{1}$ \\ ${ }^{1}$ Ankara University Faculty of Medicine, Department of Medical Oncology \\ ${ }^{2}$ Ankara University Faculty of Medicine, Department of Pathology \\ ${ }^{3}$ Ankara University Faculty of Medicine, Department of Thoracic Surgery, Ankara, TURKEY
}

To the Editor,

A 60-year-old man with prostate cancer (PC) was admitted to our hospital in October 2009 for follow up visit. He underwent radical prostatectomy for $\mathrm{PC}$ five years ago. The patient's physical examination and complete blood count, biochemical investigations, and chest $\mathrm{x}$-ray were within normal limits. The patient's carcinoembryonic antigen (CEA) and prostate-specific antigen (PSA) levels were $529 \mathrm{ng} / \mathrm{mL}$ (normal, $<3 \mathrm{ng} / \mathrm{mL}$ ) and 7.5 $\mathrm{ng} / \mathrm{mL}$ (normal, $<4 \mathrm{ng} / \mathrm{mL}$ ) respectively. Cranial, thoracic, and abdominal computerized tomography (CT) and whole body bone scan were done. The patient's chest CT scan revealed irregular, $18 \mathrm{~mm}$ nodule of the right lower lobe of lung. The cranial and abdominal CT and whole body bone scan revealed no abnormality. The endoscopic evaluation of upper and lower gastrointestinal system was normal. Since there was no evidence of metastatic site other than lung in workup, the patient underwent wedge resection of the lung lesion at December 2009 and histopathologic examination revealed the diagnosis of malignant epithelial tumor. The immunohistochemical examination showed strong staining of tumor cells with PSA, PAP and CEA but CK7, CK20, TTF-1 and SPA were negative (Figure 1). So the isolated lung metastasis of prostate adenocarcinoma was considered and bicalutamide and leuprolide acetate were started. One month later PSA and CEA level were 1.14 and $473 \mathrm{ng} / \mathrm{ml}$, respectively, and treatment was continued with leuprolide. In March 2012, he was admitted for follow up visit. The patient's CEA and PSA levels were $639 \mathrm{ng} / \mathrm{mL}$ and $1.86 \mathrm{ng} / \mathrm{mL}$ respectively.

Prostate and lung cancers together are the most common cancers in men, they constitute $43 \%$ of all cancer cases and still receive the first two places for cancer-related deaths. ${ }^{1}$ Post-mortem studies reported rates of lung metastases of prostate adenocarcinoma as $25-40 \%$. Whereas, the majority of cases, including particularly also bone metastases, there have been several reports of relapsed PC with isolated lung metastasis. Although, extraordinarily high serum level of CEA have been reported to be associated with gastrointestinal cancer such as, colon, gastric, biliary, and pancreatic cancer and breast and lung cancer, PC with high serum levels of CEA without elevation of PSA has been reported. ${ }^{2-}$ ${ }^{6}$ However, the prognostic role of CEA in the context of PC is unclear.

The prognosis in patients with PC usually depends on metastatic sites. Nonetheless, pathways of metastasis in prostate cancer are not fully understood. Solitary nodules, especially in elderly individuals with history of smoking usually, are due to primary lung cancer. Isolated pulmonary metastases of PC may be synchronous or metachronous. Metachronous metastases usually occur after median 2 years diagnosis of prostate cancer. 


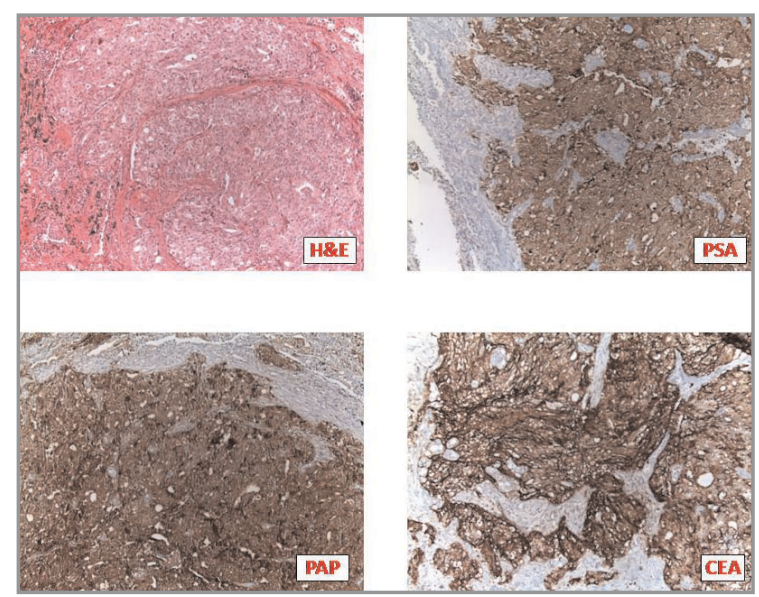

Figure 1. Histologic diagnosis of lung metastases of prostate adenocarcinoma. Hematoxylin-eosin stain of tumor cells (A). Immunohistochemical staining for PSA, PAP, and CEA.

PC, especially in elderly male patients with pulmonary nodules, should be considered in the differential diagnosis.? The immunohistochemical staining with PSA and PAP are important for differential diagnosis 3 . Although the treatment options are limited for most of the metastatic carcinomas; longterm, disease-free survival has been reported after resection for solitary lung metastases of renal cell carcinoma, colon and breast cancer and sarcomas. However, the role of resection of lung metastasis of PC regarding survival is uncertain. ${ }^{47-9}$ In our case, a complete remission was achieved with resection and currently patient is still followed without progression (27 months of disease free survival by March 2012).

In conclusion, although isolated pulmonary metastasis of PC are unusual, chest CT should be done in patient with elevated marker. We suggest that resection of pulmonary metastatic lesion could contribute to the management of PC and quality of life, as in other malignancies.

\section{REFERENCES}

1. Jemal A, Siegel R, Xu J, Ward E. Cancer statistics, 2010. CA Cancer J Clin 60: 277-300, 2010.

2. Bubendorf L, Schopfer A, Wagner $U$, et al. Metastatic patterns of prostate cancer: an autopsy study of 1,589 patients. Hum Pathol 31: 578-83, 2000.
3. Copeland JN, Amin MB, Humphrey PA, et al. The morphologic spectrum of metastatic prostatic adenocarcinoma to the lung: special emphasis on histologic features overlapping with other pulmonary neoplasms. Am J Clin Pathol 117: 552-557, 2002.

4. Quint LE, Park CH, lannettoni MD. Solitary pulmonary nodules in patients with extrapulmonary neoplasms. Radiology 217: 257-1261, 2000.

5. Kinebuchi $Y$, Noguchi W, Irie K, et al. Relapsed prostate cancer with neuroendocrine differentiation and high serum levels of carcinoembryonic antigen without elevation of prostrate-specific antigen: a case report. Int J Urol 14: 147-149, 2007.

6. Feuer JA, Lush RM, Venzon D, et al. Elevated carcinoembryonic antigen in patients with androgen-independent prostate cancer. J Investig Med 46: 66-72, 1998.

7. Eastham JA, Esensten ML, Wilson TG. Isolated pulmonary metastases from prostatic adenocarcinoma. West J Med 159: 489-490, 1993.

8. Chao DH, Higgins JP, Brooks JD. Biochemical remission after resection of prostate cancer lung metastasis. Urology 63: 584-585, 2004.

9. Wallis CJ, English JC, Goldenberg SL. The role of resection of pulmonary metastases from prostate cancer: a case report and literature review. Can Urol Assoc J 5: E104-108, 2011.

\section{Correspondence \\ Dr. Yüksel ÜRÜN \\ Ankara Üniversitesi Tıp Fakültesi \\ Medikal Onkoloji Anabilim Dalı \\ Cebeci Hastanesi \\ Dikimevi, ANKARA / TURKEY}

Tel: (+90.312) 5957112

Fax: (+90.312) 3192283

e-mail: yukselurun@gmail.com 